\title{
Conflitos de interesses na pesquisa médico-farmacológica
}

Ricardo Pires de Souza ${ }^{1}$, Abrão Rapoport ${ }^{2}$, Rogério Aparecido Dedivitis ${ }^{3}$, Cláudio Roberto Cernea ${ }^{4}$, Lenine Garcia Brandão ${ }^{5}$

\section{Resumo}

A pesquisa médico-farmacológica clínica corresponde à aplicação experimental de determinada droga em seres humanos. Seu controle visa proteger os sujeitos de efeitos adversos inaceitáveis e de ineficiência do medicamento testado diante de outras possibilidades mais eficientes. Parcerias entre a indústria farmacêutica e pesquisadores externos estabelecem potenciais conflitos de interesses. Consulta bibliográfica realizada neste estudo indica que pesquisas com financiamento da indústria farmacêutica têm proporção mais alta de resultados favoráveis e que os conflitos de interesses representam vieses, podendo alterar resultados. Há estudos que comparam a eficácia de diferentes drogas e outros que comparam seus custos. Mesmo resultados negativos devem ser publicados. Conclui que o setor privado deve financiar a ciência para beneficiar o ser humano, especialmente no combate à doença; no entanto, deve manter empenho em financiar as pesquisas sem influenciar seus desenhos, resultados e destinações, caminhando em direção ao respeito à dignidade da pessoa. Palavras-chave: Conflito de interesses. Pesquisa biomédica. Experimentação humana. Má conduta profissional. Má conduta científica.

\section{Resumen}

\section{Conflicto de interés en la investigación médico-farmacológica}

La investigación médico-farmacológica clínica corresponde a la aplicación experimental de determinado fármaco en seres humanos. Su control tiene como objetivo proteger los sujetos de efectos adversos inaceptables e ineficaces del fármaco probado. Relaciones entre la industria farmacéutica e investigadores externos establecen potenciales conflictos de intereses. En una consulta bibliográfica llevada a cabo en este estudio indica que investigaciones con financiación de la industria farmacéutica tienen proporción más elevada de resultados favorables y que los conflictos de intereses representan sesgos que pueden cambiar los resultados. Hay estudios que la eficiencia de distintos fármacos, mientras otros comparan sus costos. Todos los resultados obtenidos deben ser publicados, incluyendo cuando se los obtienen negativos. Se concluye que el sector privado deberá financiar la ciencia para beneficio del hombre, especialmente en el combate a la enfermedad. Sin embargo, La industria debería mantener su empeño en financiar las investigaciones sin influenciar su diseño, resultados y destinación caminando hacia a la comprensión de la persona en su dignidad.

Palabras-clave: Conflicto de intereses. Investigación biomédica. Experimentación humana. Mala conducta profesional. Mala conducta científica.

\section{Abstract \\ Conflicts of interest in the medical pharmacological research}

The clinical medical pharmacological research corresponds to the experimental application of specific drug in human beings. Such application aims to protect them from unacceptable adverse effects and its inefficiency when comparing with other possibilities, more efficient. Partnerships between the pharmaceutical industry and external researchers establish potential conflict of interest. Literature use for this work indicates that researches performed under the sponsorship of pharmaceutical industry have a high rate of favorable results, and the conflicts of interest represent gaps which may interfere the result. There are studies that compare the efficiency of different drugs, whereas others compare their costs. All results should be published, even when negative. The present work concludes that the private sector must sponsor the science in order to improve human beings, especially to avoid diseases. However, it must keep its engagement in sponsoring the research with any influence on its methods, results and application, for a respectful understanding of the dignity of a person. Key words: Conflict of interest. Biomedical research. Human experimentation. Professional misconduct. Scientific misconduct.

1. Doutor ricapires@uol.com.br - Hospital Heliópolis. 2. Livre-docente arapoport@terra.com.br - Universidade de São Paulo, Hospital Heliópolis 3. Livre-docente dedivitis.hns@uol.com.br-Universidade de São Paulo 4. Livre-docente cerneamd@uol.com.br-Universidade de São Paulo 5. Livre-docente leninegb@uol.com.br - Universidade de São Paulo, São Paulo/SP, Brasil.

Correspondência

Abrão Rapoport - Rua Cônego Xavier, 276 CEP 04231-030. São Paulo/SP, Brasil.

Declaram não haver conflito de interesse. 
A pesquisa médico-farmacológica clínica corresponde à aplicação, em caráter experimental, de determinada droga cujas ações se quer estudar, em seres humanos, de forma controlada. O controle da aplicação visa proteger os pacientes sujeitos do ensaio clínico tanto de efeitos adversos inaceitáveis quanto de ineficiência do medicamento testado diante de outras possibilidades claramente mais eficientes, podendo o processo de pesquisa ser interrompido a qualquer momento se for detectada, por meio de resultados parciais, a sua inadequação. Tal controle exige acompanhamento permanente e estreito de supervisores externos e isentos.

A indústria farmacêutica necessita estabelecer parcerias com instituições e médicos pesquisadores externos aos seus quadros de colaboradores para realizar a fase clínica de teste de qualquer droga em relação a qual deseja autorização governamental para implantação comercial. E é neste momento que se estabelecem os conflitos de interesses na pesquisa médico-farmacológica. A forma que a indústria farmacêutica tem de promover a fase clínica da pesquisa em parceria com instituições e médicos pesquisadores externos que se responsabilizem pelas mesmas é financiar os estudos, fornecendo material e dinheiro.

A indústria farmacêutica pode contratar empresas de consultoria que possuam em seus quadros médicos-pesquisadores capazes de avaliar produtos específicos. Outras vezes, as pesquisas ficam a cargo de médicos-pesquisadores independentes frequentemente doutores, pós-doutores e livresdocentes - que detêm personalidades jurídicas habilitadas a receber o financiamento da indústria farmacêutica. Em qualquer caso, entretanto, os possíveis benefícios dos estudos para as instituições não devem influir na atitude metodológica dos seus pesquisadores, não devendo ter influência nos desenhos, na avaliação e divulgação dos resultados.

O que permanece indefinido é como se estabelecem os honorários do médico-pesquisador e sua equipe no financiamento. A questão fundamental é se a relação financeira pode interferir na aplicação da metodologia condicionando os resultados da pesquisa. Supostamente, não há motivos para alguém trabalhar de graça, o que inclui o médicopesquisador e sua equipe. Nestes casos, o valor do honorário é assunto que, segundo o pacto social, não interessa a ninguém senão aos contratantes.

Assim, contemplados os princípios éticos da Declaração de Helsinque de 1964 e suas modificações posteriores (até 2008), e desde que o rigor metodológico seja atendido, sempre sob a supervisão de órgãos colegiados autônomos e considerando a exigência de cumprir prerrogativas legais, não há problema em que um médico-pesquisador teste clinicamente, a pedido da indústria farmacêutica, determinada droga visando sua implantação comercial e receba, assim como sua equipe, remuneração por esse trabalho.

O compromisso do pesquisador, em qualquer circunstância, sempre deverá ser o de respeitar princípios éticos e manter isenção metodológica, aplicando os critérios definidos pelo estudo com o maior rigor ético e científico possível. Nesse sentido, deve revelar prontamente à comunidade acadêmica os resultados de seu trabalho, quaisquer que sejam favoráveis ou desfavoráveis para o financiador.

O resultado favorável pode significar nova patente e lucro. $O$ resultado desfavorável pode representar perda significativa de investimento, tempo e expectativa do lucro. Idealmente, isso não deveria influenciar médicos-pesquisadores e seria de se esperar que a proporção de resultados favoráveis e desfavoráveis não poderia ser muito diferente entre pesquisas financiadas pela indústria farmacêutica e as provindas de fontes independentes, geralmente produzidas em instituições acadêmicas. Mas, como será observado a seguir, não é o que ocorre ${ }^{1}$.

\section{Conflitos de interesses na pesquisa}

Há evidências na literatura de que as pesquisas realizadas com financiamento da indústria farmacêutica têm melhor proporção de resultados favoráveis do que as levadas a cabo em instituições independentes ${ }^{2,3,4}$. Jang et $a l^{2}$ avaliaram 236 análises econômicas de uso de medicamentos apresentados em congressos de oncologia e hematologia estadunidenses com conflitos de interesses; e identificaram que $89,9 \%$ dessas análises foram favoráveis ao financiador da pesquisa, direta ou indiretamente. Embora os resultados variem na literatura, existem evidências consistentes de que a presença de conflitos de interesses é prevalente ${ }^{3,4}$.

Os conflitos de interesses podem representar poderoso viés na pesquisa científica, alterando o resultado, produzindo má ciência e, mais grave, afetando negativamente a saúde dos participantes, já que efeitos adversos inesperados e ausência da ação prevista podem decorrer de falsos resultados. Esse viés pode ser premeditado ou involuntário, em maior ou menor proporção, mas, seja de que modo for, existe e deve ser levado em consideração. 0 experimentador é parte do experimento e sua supos- 
ta isenção, assim como a inflexibilidade do método científico, é somente um ideal, não algo real.

A pesquisa na indústria farmacêutica evita sistematicamente, na fase clínica, testar um novo medicamento, comparando-o a outra droga similar já existente, preferindo compará-lo a placebo ${ }^{5}$. Apenas isso já representa um viés no desenho da pesquisa, decorrente do conflito de interesse. Já nas análises econômicas promovidas pela indústria farmacêutica, comparações de análises de custo-benefício destinadas às fontes pagadoras costumam comparar diretamente seu produto com os dos concorrentes diretos ou indiretos, buscando evidenciar a ineficiência, em última análise financeira, de produtos concorrentes.

Também chama a atenção o fato de que, em trabalhos apresentados em congressos e artigos publicados em revistas especializadas, seja frequente a não declaração de conflitos de interesses ${ }^{2}$. Jang et $a$ l identificaram 27 análises econômicas de uso de medicamentos em um universo amostral de 356 análises, nas quais os autores eram empregados ou consultores da indústria farmacêutica, mas não haviam declarado seu conflito de interesse ${ }^{2}$. Atualmente, a declaração de conflitos de interesses é feita pelo próprio autor (ou autores) voluntariamente, não havendo controle externo rígido como contraponto.

A questão da não publicação de resultados desfavoráveis pela indústria farmacêutica pode contribuir para a desproporção de pesquisas favoráveis em relação às das instituições acadêmicas de pesquisa. Este não é um mal exclusivo à pesquisa conduzida pela indústria farmacêutica, mas nela parece ser mais premeditado.

\section{Considerações finais}

O consórcio entre tecnologia, ciência e comércio é inerente ao próprio desenvolvimento industrial e faz parte dos fundamentos da civilização contemporânea. A simbiose entre todos esses elementos e o poder também embasa as estruturas simbólicas e o comportamento das sociedades hodiernas pautadas pelo modo de vida ocidental. Ao financiar a ciência e a tecnologia no sentido de aliviar o sofrimento humano, promover seu bem-estar, prolongar sua existência e até mesmo melhorá-lo, o comércio age dentro de elevado aspecto ético. Em seu aspecto não ético, se une ao poder em busca de lucro exagerado e termina, dentre outras possibilidades, por produzir má ciência e tecnologias potencialmente perigosas.
A pesquisa biotecnológica em geral e a pesquisa médico-farmacológica em particular lidam com a dignidade da pessoa no seu momento mais crucial: o enfrentamento da morte, o que impõe peculiaridades às simbioses acima descritas. Embora o fomento e o financiamento da pesquisa médicofarmacológica pela indústria farmacêutica sejam simultaneamente desejáveis e inevitáveis, seu aspecto não ético deve ser preventivamente contido com rigor. Bioética e justiça são, aqui, as pedras fundamentais desta contenção.

Ensaios clínicos são experimentação in anima nobile. Se sua supervisão já é, atualmente, bastante rigorosa, este rigor deveria ser levado ao extremo. $O$ desenho dos ensaios clínicos deveria estar sujeito à apreciação de colegiado externo isento e sob controle de órgãos governamentais. Nesse sentido, por exemplo, estudos com utilização de placebo deveriam ser evitados ou proscritos ${ }^{6,7}$.

Estudos com conflitos de interesses declarados deveriam ter atenção redobrada ou mesmo tratamento específico pelos conselhos editoriais das revistas especializadas e pelos comitês científicos dos congressos. A caracterização do tipo de conflito de interesse, em cada caso, deve ser clara, o que inclui declaração de recebimento de honorários por médicos pesquisadores independentes. A não declaração de conflitos de interesses deve ser tratada com rigor. Casuística, método e resultados de qualquer pesquisa biomédica devem ser compulsoriamente comunicados.

Deve existir um espaço no qual casuística, método e resultados de pesquisas não publicadas sejam obrigatoriamente depositados e que possam ser consultados por especialistas. Tal local poderia ser virtual e deveria estar sob controle dos Estados. Metanálises deveriam ser atualizadas sistematicamente, comparando resultados de drogas, destacando pesquisas sob conflito de interesse e utilizando material não publicado, mas depositado em local apropriado, como sugerido acima. Na relação entre a indústria farmacêutica e a pesquisa médico-farmacológica em sua fase clínica, idealmente, a indústria deveria manter seu empenho em financiar a pesquisa abrindo mão proativa e completamente de qualquer possibilidade de influência em seus desenhos, resultados e destinações editoriais. É possível que, em futuro não sabemos o quão próximo, qualquer atitude diferente da expressa acima por parte da indústria farmacêutica possa ser interpretada como ruptura do pacto social.

Hoje, caminhamos com nossas contradições em direção à compreensão da pessoa em sua dignidade como valor supremo da civilização. Cada in- 
divíduo humano percebido como único e irrepetível e cuja existência se situa acima de qualquer preço. Da busca da universalidade nasce a justiça. Por fim, muitas das análises e reflexões aqui expressas podem ser estendidas sem muita dificuldade para toda a pesquisa biotecnológica.

\section{Referências}

1. Massud M. Conflito de interesses entre os médicos e a indústria farmacêutica. Rev. bioét. (Impr.). 2010;18(1):75-91.

2. Jang S, Chae YK, Majhail NS. Financial conflicts of interest in economic analyses in oncology. Am J Clin Oncol. 2011;34(5):524-8.

3. Jagsi R, Sheets N, Jankovic A, Motomura AR, Amarnath S, Ubel PA. Frequency, nature, effects, and correlates of conflicts of interest in published clinical cancer research. Cancer. 2009;115(12):2783-91.

4. Kesselheim AS, Lee JL, Avorn J, Servi A, Shrank WH, Choudhry NK. Conflict of interest in oncology publications: a survey of disclosure policies and statements. Cancer. 2012;118(1):188-95.

5. Angel M. A verdade sobre os laboratórios farmacêuticos: como somos enganados e o que podemos fazer a respeito. Rio de Janeiro: Record; 2008.

6. Garrafa V, Prado MM. Alterações na Declaração de Helsinque: a história continua. Bioética. 2007;15(1):11-25.

7. Conselho Federal de Medicina. Resolução CFM n 1.885, de 23 de outubro de 2008. [Internet]. É vedado ao médico participar de pesquisa envolvendo seres humanos utilizando placebo, quando houver tratamento disponível eficaz já conhecido. Diário Oficial da União. 27 out. 2008 [acesso 20 jun. 2012];Seção I:90. Disponível: http://www.portaldabioetica.com.br/legislacao/27.pdf

\section{Participação dos autores}

Abrão Rapoport: estruturação do texto; Ricardo Pires de Souza e Rogério Aparecido Dedivitis: revisão da literatura e formatação do texto; Cláudio Roberto Cernea e Lenine Garcia Brandão: revisão crítica e formatação do texto.

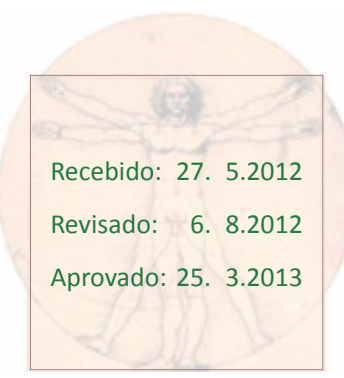

